\title{
Fibrous Hamartoma of Infancy
}

National Cancer Institute

\section{Source}

National Cancer Institute. Fibrous Hamartoma of Infancy. NCI Thesaurus. Code C3942.

A poorly circumscribed neoplasm arising from the soft tissues in infants. It is characterized by the presence of bland fibroblastic spindle cells, collagenous stroma formation, primitive mesenchymal round cells, and mature fat cells. These components combined form a distinct organoid pattern. 